ARTICLE

DOI: $10.1038 / \mathrm{s} 41467-018-03501-8$

\title{
Engineering enhanced cellobiohydrolase activity
}

Larry E. Taylor II', Brandon C. Knott ${ }^{1}$, John O. Baker ${ }^{1}$, P. Markus Alahuhta', Sarah E. Hobdey ${ }^{1}$, Jeffrey G. Linger ${ }^{2}$, Vladimir V. Lunin¹, Antonella Amore1, Venkataramanan Subramanian¹, Kara Podkaminer ${ }^{1}$, Qi Xu1, Todd A. VanderWall' ${ }^{1}$ Logan A. Schuster ${ }^{1}$, Yogesh B. Chaudhari ${ }^{1,3}$, William S. Adney ${ }^{1}$, Michael F. Crowley (1) ${ }^{1}$, Michael E. Himmel ${ }^{1}$, Stephen R. Decker (1) ${ }^{1} \&$ Gregg T. Beckham (i) ${ }^{2}$

Glycoside Hydrolase Family 7 cellobiohydrolases ( $\mathrm{GH} 7 \mathrm{CBHs}$ ) catalyze cellulose depolymerization in cellulolytic eukaryotes, making them key discovery and engineering targets. However, there remains a lack of robust structure-activity relationships for these industrially important cellulases. Here, we compare CBHs from Trichoderma reesei (TrCel7A) and Penicillium funiculosum (PfCel7A), which exhibit a multi-modular architecture consisting of catalytic domain (CD), carbohydrate-binding module, and linker. We show that PfCel7A exhibits $60 \%$ greater performance on biomass than $\operatorname{TrCel7A}$. To understand the contribution of each domain to this improvement, we measure enzymatic activity for a library of $\mathrm{CBH}$ chimeras with swapped subdomains, demonstrating that the enhancement is mainly caused by PfCel7A CD. We solve the crystal structure of PfCel7A CD and use this information to create a second library of $\operatorname{TrCe} 77 \mathrm{~A} C D$ mutants, identifying a $\operatorname{TrCel7A}$ double mutant with near-equivalent activity to wild-type PfCel7A. Overall, these results reveal $\mathrm{CBH}$ regions that enable targeted activity improvements.

\footnotetext{
${ }^{1}$ Biosciences Center, National Renewable Energy Laboratory, Golden, CO 80401, USA. ${ }^{2}$ National Bioenergy Center, National Renewable Energy Laboratory, Golden, CO 80401, USA. ${ }^{3}$ Life Sciences Division, Institute of Advanced Study in Science and Technology (IASST), Guwahati, India. These authors contributed equally: Larry E. Taylor II, Brandon C. Knott, John O. Baker, P. Markus Alahuhta. Correspondence and requests for materials should be addressed to S.R.D. (email: steve.decker@nrel.gov) or to G.T.B. (email: gregg.beckham@nrel.gov)
} 
P lant cell walls are highly evolved heterogeneous composite structures, which are a significant challenge to deconstruct $^{1,2}$. The recalcitrant polymers cellulose and hemicellulose comprise the majority of plant cell wall polysaccharides. To date, many processes have been developed to produce renewable fuels and chemicals from biomass-derived sugars, ranging from ethanol to higher alcohols via fermentation in genetically modified organisms ${ }^{3}$ to hydrocarbons produced biologically ${ }^{4}$ or catalytically ${ }^{5}$. Accordingly, there is significant impetus to develop cost-effective sugar production methods for upgrading to fuels and chemicals. Most current leading options to produce sugars from lignocellulose utilize a thermochemical pretreatment step that renders the plant cell wall more amenable to the effective application of enzyme cocktails in a second step, which deconstructs cellulose and hemicellulose to soluble sugars ${ }^{6}$. The enzymatic hydrolysis step alone represents a significant fraction (up to 25\%) of the operating and capital cost of lignocellulosic biofuel production ${ }^{\text {, }}$, and towards this, significant efforts have been focused on development of enhanced industrial enzymes $^{8,9}$.

Many biomass-degrading enzymes under development today are based on fungal cellulase secretomes. The emphasis on fungal cocktails originated from the isolation of the fungus Trichoderma reesei in the late 1940s, which has grown into an important platform for the production of cellulases at extremely high protein titers ${ }^{8}$. In most eukaryotic cellulase systems ${ }^{10}$, and especially in cellulolytic filamentous fungi, Glycoside Hydrolase Family 7 (GH7) cellobiohydrolases (CBHs) are often the main enzymes produced in natural secretomes ${ }^{8}$, likely because these enzymes provide the majority of the hydrolytic activity for cellulose conversion to glucose. GH7 cellulases are particularly important to industrial fungal cellulase cocktails, as the current lignocellulosic biorefineries operating worldwide predominantly use fungal-based cellulase systems. $\mathrm{GH} 7 \mathrm{CBHs}$ have therefore been the focus of many structural and biochemical studies and primary targets for cellulase engineering $8,11-22$. To date, many $\mathrm{GH} 7 \mathrm{CBH}$ structures have been reported including the wellstudied $T$. reesei Cel7A, denoted $T r$ Cel7A. As with many GH7 CBHs, $\operatorname{TrCel7A}$ is a multi-modular enzyme with a Family 1 carbohydrate-binding module (CBM), which is responsible for binding to cellulose, connected to the catalytic domain (CD) by a flexible, glycosylated linker $8,11,12,23,24$, as illustrated in Fig. 1.
Rational engineering of $\mathrm{CBHs}$ requires insight into the structure and function of the individual domains, as well as the entire enzyme complexed with cellulose. Hypotheses as to the role of the individual domains have evolved since the first structural studies of multi-domain cellulases ${ }^{11,12,24,25}$. The Family $1 \mathrm{CBM}$ is thought to be primarily responsible for increasing the binding affinity of a given cellulase $C D$ to the cellulose substrate, thus ensuring a high catalyst concentration at the solid surface. Many protein engineering studies conducted with the CBM have highlighted the role of aromatic and polar residues on binding ${ }^{26-28}$ and more recently, the importance of glycosylation on binding and stability ${ }^{29-31}$. Similarly, the linker acts as a flexible tether between the CBM and $\mathrm{CD}^{32}$, and was demonstrated to aid cellulose binding ${ }^{33}$. The $\mathrm{CD}$ in $\mathrm{GH} 7 \mathrm{CBH}$ exhibits a $50 \AA$-long tunnel wherein a single cellulose chain is threaded, complexed, and hydrolyzed to the disaccharide cellobiose. The putative catalytic cycle of Cel7A includes surface binding, location of a free cellulose chain end, chain complexation, hydrolysis, product expulsion, and processivity until the cellulase consumes an entire chain or becomes stuck due to obstacles in its path ${ }^{34,35}$.

Despite efforts to engineer GH7 CBHs for improved activity, relatively few successes have been reported. For direct improvement of specific activity, high-throughput screening approaches are limited because cellulose deconstruction requires many hours to days to reach relevant conversions. Moreover, for fungal enzymes, glycosylation is important for activity ${ }^{36,37}$, precluding many standard expression hosts, and native filamentous fungi are not yet typically amenable to high-throughput expression. Thus, nascent cellulase engineering efforts have been limited to screening relatively small sets of rationally guided or computationally designed mutations for higher thermal stability and subsequent gains in activity at higher conversion temperatures $^{18-20,38-43}$. To date, there are few studies that demonstrate significant increases in activity on industrially relevant substrates above that reported for several well-studied GH7 CBHs. Indeed, genomics and metagenomics studies have elucidated a broad library of enzymes in many of the most important GH families for industrial biomass conversion, yet self-consistent activity comparisons amongst these are scarce ${ }^{8}$. This lack of information on GH7 CBHs represents a remaining gap in cellulase engineering that limits our collective ability to develop reliable

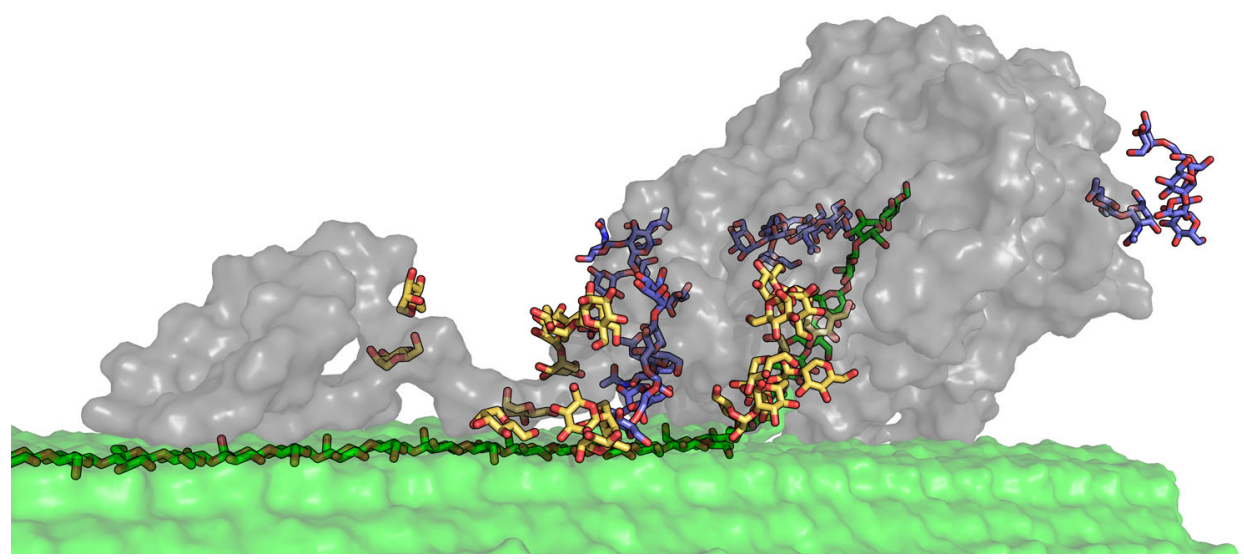

Fig. 1 Multi-modular structure of Family 7 cellobiohydrolases. The GH Family $7 \mathrm{CBH}$ from $T$. reesei is shown in the catalytically active complex on a cellulose microfibril. Shown in gray are the enzyme domains: at right is the catalytic domain (CD), at left is the carbohydrate-binding module (CBM), and connecting

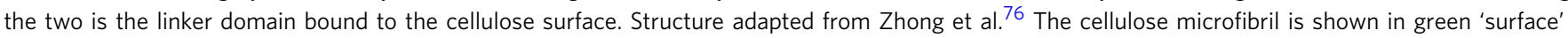
representation; 'sticks' are also shown for the strand upon which Cel7A is complexed. O-glycans are shown on the linker and CBM in yellow; $N$-glycans are shown in dark blue on the catalytic domain 
structure-activity relationships for these important natural and industrial enzymes.

Towards the ultimate goal of developing more detailed structure-activity relationships in $\mathrm{GH} 7 \mathrm{CBHs}$, here we report the detailed characterization of a multi-modular $\mathrm{GH} 7 \mathrm{CBH}$ from the fungus Penicillium funiculosum ${ }^{44}$, denoted PfCel7A. This enzyme exhibits a greater than $1.6 \times$ superiority in performance over the well-studied $\operatorname{TrCel7A}$ on a process relevant biomass substrate. To understand the reasons for this greater activity, we conduct domain swapping experiments with the CBM, linker, and CD from the two parent enzymes to create a library of $\operatorname{TrCel7A}$ and $P f C e l 7 A$-based chimeras and compare their performance; these experiments suggest that the PfCel7A CD is the primary, but not the only, driver of the activity differences in the parent enzymes. From there, we solve the X-ray crystal structure of the PfCel7A $\mathrm{CD}$, from which we design a second mutant library wherein eight changes are swapped individually into the $\operatorname{TrCel7A}$ parent enzyme. This reveals two mutations that, when combined, result in a $\operatorname{TrCel7A}$-parent based mutant with performance on pretreated biomass approaching that of the PfCel7A parent, thus revealing two important motifs in $\mathrm{GH} 7 \mathrm{CBH}$ s that can result in dramatic performance differences. The functional importance of these two motifs is explored via molecular dynamics (MD) simulations of the enzymes both in solution and complexed on a cellulose microfibril.

\section{Results}

Characterization of CBH PfCel7A. The PfCel7A and TrCel7A enzymes were expressed in a recently reported $T$. reesei expression system ${ }^{45}$. Enzyme production and purification are described in the Methods. The Michaelis-Menten kinetics of both enzymes on the small molecule substrate $p N P L, T_{\max }$ (calorimetrically measured approximate midpoint of thermal denaturation), and $\mathrm{pH}$ and temperature activity optima are summarized in Supplementary Table 1 and Supplementary Fig. 1.

Figure 2 shows the activity comparisons between $\operatorname{TrCel7A}$ and PfCel7A on dilute acid pretreated corn stover (PCS) at $40^{\circ} \mathrm{C}$. Although $40^{\circ} \mathrm{C}$ is lower than the optimal temperature for these $\mathrm{CBHs}$, enzymatic saccharification in the biorefinery typically employs the simultaneous saccharification and fermentation (SSF) approach. SSF operating temperature is limited by the fermentative organism and rarely has SSF operation achieved an operating temperature significantly above $40^{\circ} \mathrm{C}^{46}$. $\mathrm{CBH}$ activity assays were performed in the presence of a highly active Family 5 endoglucanase (E1) from Acidothermus cellulolyticus ${ }^{47}$ and a $\beta$-glucosidase from Aspergillus niger for enzyme synergy and to alleviate product inhibition. We utilize this cocktail of three enzymes (rather than an isolated $\mathrm{CBH}$ ) because (1) this is the context that $\mathrm{CBH}$ s are used industrially and (2) the rate-limiting step in the $\mathrm{CBH}$ processive cycle is different with and without accessory enzymes ${ }^{48,49}$. The total enzyme loading was $30.4 \mathrm{mg}$ total enzyme per gram of cellulose with a mass ratio of 56:3.8:1 of the GH7 CBH:GH5 endoglucanase: $\beta$-glucosidase. Cellulase performance is measured as the time to reach $80 \%$ conversion (via a double exponential fit). For industrial purposes and technoeconomic modeling, the time-to-target with $80 \%$ glucan conversion is the primary relevant metric used here to assess cellulase performance 7,50 . Fig. 2a shows that wild-type (WT) PfCel7A reaches $80 \%$ conversion more than $1.6 \times$ as fast $(38 \mathrm{~h}$ relative to $62 \mathrm{~h}$ ) compared to WT TrCel7A. (Also note that the conclusions reached in what follows are invariant to the choice of conversion target; if one chooses any conversion target between 50 and $80 \%$, the activity superiority of $P f C e l 7 \mathrm{~A}$ over $\operatorname{TrCel7A}$ is always greater than a factor of 1.6; see Supplementary Table 2.)

The results from the screening are shown in Fig. 2b. Based on the time to reach $80 \%$ conversion, the performance of the

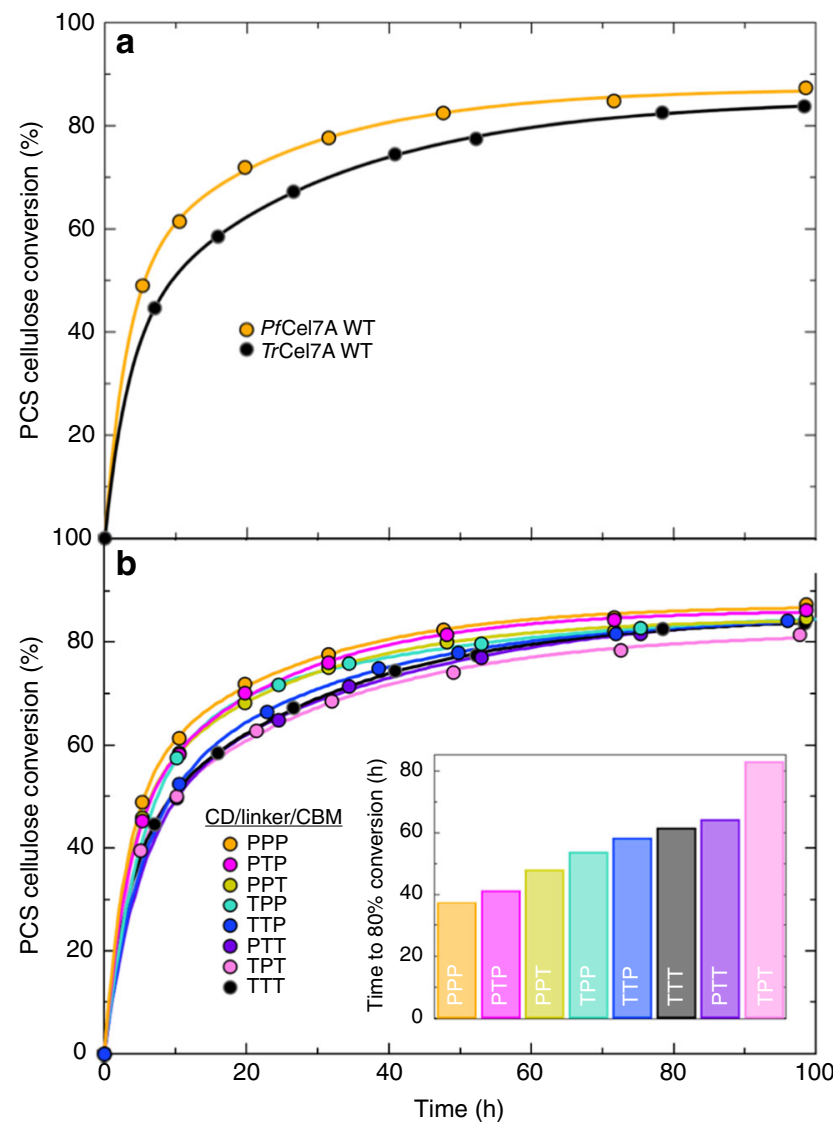

Fig. 2 Activity data on dilute acid pre-treated corn stover. Glucan conversion is shown as a function of time on PCS for a wild-type PfCel7A and wild-type $\operatorname{TrCel7A}$ and $\mathbf{b}$ the domain swap chimera library. The $P$ and $T$ stand for $P$. funiculosum and $T$. reesei, respectively in the domain architecture in the order of $C D$, linker, and CBM. The lines represent double-exponential fits to the data. These assays were performed at $T=40^{\circ} \mathrm{C}$ and $\mathrm{pH}=5.0$. The inset graph shows the time to $80 \%$ conversion (in hours) of the double exponential fit to each data trend. Graphs with these fits are available in Supplementary Fig. 2. Experiments were performed in triplicate; error bars represent the standard error of the mean (SEM) and are smaller than the data markers

PfCel7A parent is slightly reduced upon swapping either the linker or CBM for the corresponding TrCel7A domain (PTP and PPT, respectively). If both domains are swapped (PTT), however, performance is reduced to that of WT TrCel7A. Conversely, swapping the linker of the $\operatorname{TrCel7A}$ parent reduces the performance (TPT), whereas swapping the CBM or the CBM/ linker for that of PfCel7a (TTP and TPP, respectively) improves $\operatorname{TrCel7A}$ performance. Given the lack of a completely uniform trend in terms of the effect of a single domain on activity, clearly there are interactions between domains that require further study $^{51}$. Though there is only one outlier in our study (and the effect is minor), these results demonstrate a knowledge gap in the functional interconnectedness of the CBM, linker, and catalytic domain in conversion of cellulose to soluble sugars. In addition, this result suggests that significant performance improvements can be made to cellulases based on natural diversity screening and chimera library generation.

Structural characterization. Motivated by the superior performance imparted by the PfCel7A CD relative to that of $T r C e l 7 \mathrm{~A}$, we sought to understand the structural roots of this functional difference by solving the X-ray crystal structure of the PfCel7A 
$\mathrm{CD}$ (PDB code $4 \mathrm{XEB}$ ) to $1.70 \AA$ resolution (Table 1 ), which is shown in Fig. 3 aligned with $\operatorname{TrCel7A}(\mathrm{PDB} \text { code } 4 \mathrm{C} 4 \mathrm{C})^{17}$. A stereo image of a portion of the electron density map is available in Supplementary Fig. 3.

The backbones of the tunnel-enclosing loops (B2, B3, and A3 in particular) in PfCel7A overlay that of $\operatorname{TrCel7A}$ quite closely. However, the substrate-binding tunnel of PfCel7A tends to expose the substrate to solution more as a result of a tyrosine to alanine substitution ( $\operatorname{TrCel7A}$ Tyr371 is replaced by PfCel7A Ala375). As a result, the exposure of a bound ligand to solvent is

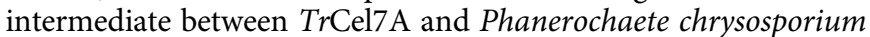
Cel7D (PcCel7D, Supplementary Fig. 4). PfCel7A possesses the B3 loop (aka the "exo loop") that PcCel7D lacks ${ }^{15}$. This structural feature has been demonstrated to have functional significance, impacting processivity, product inhibition, and activity on cellulose $^{52}$. A significant difference in the main binding tunnel loops between $\operatorname{TrCel7A}$ and PfCel7A is that of a shortened A1 loop in $P f C e l 7 \mathrm{~A}$, corresponding to a three-residue deletion in PfCel7A (A100, Q101, K102 TrCel7A numbering). In GH7 crystal structures, there are three basic structural modes for this loop, with $\operatorname{TrCel7A}$ possessing the intermediate length loop. The elongated A1 loop is exhibited by Heterobasidion irregulare Cel7A $(\text { HirCel7A })^{53}$, Limnoria quadripunctata Cel7B $(\text { LqCel7B })^{14}$, Melanocarpus albomyces Cel7B $(\mathrm{MaCel7B})^{16}$, and Humicola grisea var. thermoidea Cel7A $(\mathrm{HgCel7A})^{54}$. PfCel7A features the shortest of these modes, also displayed by PcCel7D, Talaromyces emersonii Cel7A (TeCel7A) ${ }^{13}$, and Trichoderma harzianum Cel7A (ThCel7A) ${ }^{22}$. In TrCel7A, this loop includes two glutamine residues, both of which could interact with the crystalline cellulose surface and one of which is within hydrogen bonding distance of the extracted cellulose chain. PfCel7A lacks these interactions (one is deleted and the other is repositioned due to the shorter loop), in addition to losing a salt bridge between Lys102 and Glu408, the latter of which is located on the A2 loop.

\begin{tabular}{|ll}
\hline Table 1 X-ray data collection and refinement statistics \\
& Penicillium funiculosum Cel7A \\
\hline Data collection & \\
Space group & \\
Cell dimensions & \\
$a, b, c(\AA)$ & $71.0,61.8,85.8$ \\
$\alpha, \beta, \gamma\left({ }^{\circ}\right)$ & $90.0,98.8,90.0$ \\
Resolution $(\AA)$ & $50.01 .7(1.8-1.7)$ \\
$R_{\text {merge }}$ & $0.103(0.400)$ \\
I/ $\sigma$ l & $13.0(1.7)$ \\
Completeness $(\%)$ & $99.0(94.4)$ \\
Redundancy & $8.6(2.1)$ \\
Refinement & \\
Resolution $(\AA)$ & $50.01 .7(1.74-1.7)$ \\
No. reflections & 37,520 \\
$R_{\text {work }} / R_{\text {free }}$ & $0.138(0.296) / 0.203(0.430)$ \\
No. atoms & \\
Protein & 3311 \\
Ligand/ion & 148 \\
Water & 857 \\
B-factors & \\
Protein & 11.4 \\
Ligand/ion & 17.0 \\
Water & 25.5 \\
R.m.s. deviations & \\
Bond lengths $(\AA)$ & 0.018 \\
Bond angles $\left({ }^{\circ}\right)$ & 1.904 \\
\end{tabular}

Structure was generated from a single crystal. Statistics for the highest resolution bin are in parenthesis
Relatively close to the tunnel entrance is another potentially significant difference: PfCel7A lacks a disulfide bridge that TrCel7A possesses. In all, $\operatorname{TrCel7A}$ has ten total disulfide bridges and PfCel7A contains nine. The tenth disulfide bond between Cys4 and Cys72 (TrCel7A) is relatively rare amongst GH7 members with solved structures, exhibited only in $\operatorname{TrCel7A}$, ThCel7A, and $\mathrm{HgCel7A}$.

Construction of a CD mutant library. Subsequent to solving the PfCel7A crystal structure, we identified seven areas of the enzyme wherein the structure differed significantly from that of $\operatorname{TrCel7A}$. Each of these motifs was swapped into the corresponding region of the $\operatorname{TrCel7A}$ parent. A complete description of these catalytic domain mutants (T1-T7) is found in Supplementary Figs. 5 and 6.

Two of these CD mutants, namely T1 (removal of the tenth disulfide bridge by C4G and C72A mutations) and T3 (threeresidue deletion in the A1 loop), exhibited higher activity on PCS than the WT $\operatorname{TrCel7A}$ parent enzyme (Fig. 4). These two mutations (T1/T3) were then combined into the same mutant. Interestingly, with the mutation of two localized regions of the parent enzyme $\operatorname{TrCel7A}$, hydrolytic activity nearly matches that of the PfCel7A WT, representing an improvement of $>60 \%$ in terms of the time to $80 \%$ conversion (as measured by a double exponential fit to the conversion as a function of time, Supplementary Fig. 7).

We also performed the converse experiment; that is we introduced the features of $\operatorname{TrCel7A}$ corresponding to CD mutants T1 and T3 into the PfCel7A parent enzyme to see whether the performance of PfCel7A could be significantly diminished with the introduction of these limited mutations. In particular, we created CD double mutant $\mathrm{P} 1 / \mathrm{P} 3$. As before, we see that with these two limited modifications, the activity can be modulated back to that of the WT TrCel7A (Fig. 4). Whether introducing these two features (into PfCel7A) or removing them (from $\operatorname{Tr}$ Cel7A), it is clear that activity can be modulated between the upper bound of WT PfCel7A and the baseline of WT TrCel7A.

Mechanistic insight via molecular simulations. To further understand the significant performance differences from relatively modest structural changes, we performed $1 \mu$ s molecular dynamics (MD) simulations of WT PfCel7A CD, WT TrCel7A $\mathrm{CD}$, and the $\mathrm{CD}$ double mutant $\mathrm{T} 1 / \mathrm{T} 3$ (TrCel7A parent) $\mathrm{CD}$ in solution and the latter two enzymes with the $\operatorname{TrCel7A}$ linker/ CBM complexed on a cellulose microfibril.

The effect of the disulfide removal (C4G, C72A) is observed most clearly in the solution simulations. The tunnel entrance (roughly residues $3-12$ ) is clearly more flexible in the double mutant, as illustrated by comparing the RMSF profiles (Supplementary Fig. 8). This increased flexibility is unique to the tunnel entrance-no other region of the enzyme that interacts with the substrate exhibits any significant difference. As a result, the ligand in the mutant enzyme is considerably more flexible and explores a much wider range of space near the tunnel entrance than WT $\operatorname{TrCel7A}$ (Fig. 5a-c). The increased flexibility of the enzyme and ligand upon disulfide removal can, at least in part, be attributed to the loss of a stable hydrogen bond in WT TrCel7A between Gln7 and the glucose in the -7 binding site (Fig. $5 \mathrm{~d}$ ). In the absence of the disulfide, the short loop containing Gln7 moves away from the substrate, the hydrogen bond is no longer present, and the ligand moves more freely. As expected with increased flexibility, ligand solvation also increases at the binding tunnel entrance. The three binding sites nearest to the tunnel entrance have, on average, 2-3 more water molecules nearby in the CD mutant T1/ T3 (near the levels of PfCel7A WT) than their counterparts in $\operatorname{TrCel7A}$ WT (Supplementary Fig. 9). 


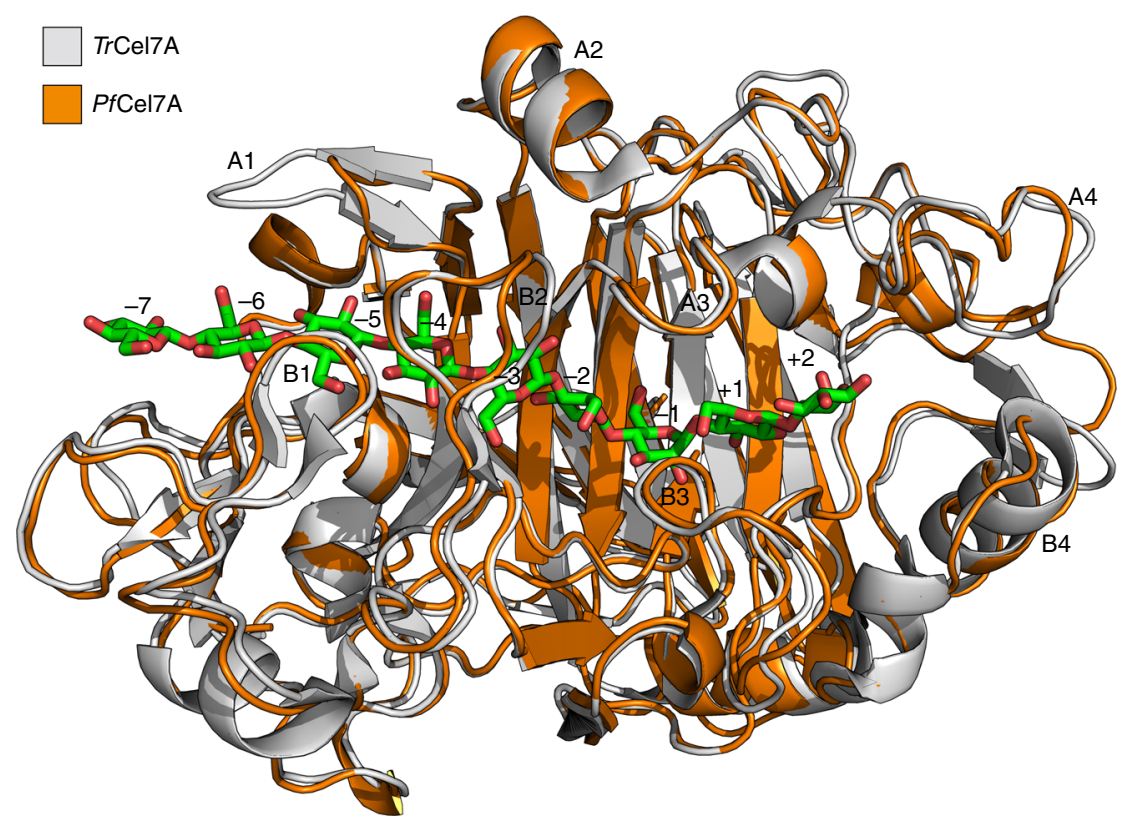

Fig. 3 The structure of PfCel7A. The structure of PfCel7A (PDB code 4XEB), shown in orange, along with that of the canonical GH7 CBH TrCel7A (PDB code $4 C 4 C)$ in light gray. The nine substrate binding sites $(-7$ to +2$)$ and the eight loops that form the substrate binding tunnel (A1, B1, etc.) are labeled according to the standard convention. The cellononaose ligand from the TrCel7A Michaelis complex (PDB code 4C4C) is shown in green 'sticks'. For key areas of differences in these structures that inspired the construction of a library of CD mutants, see Supplementary Fig. 5

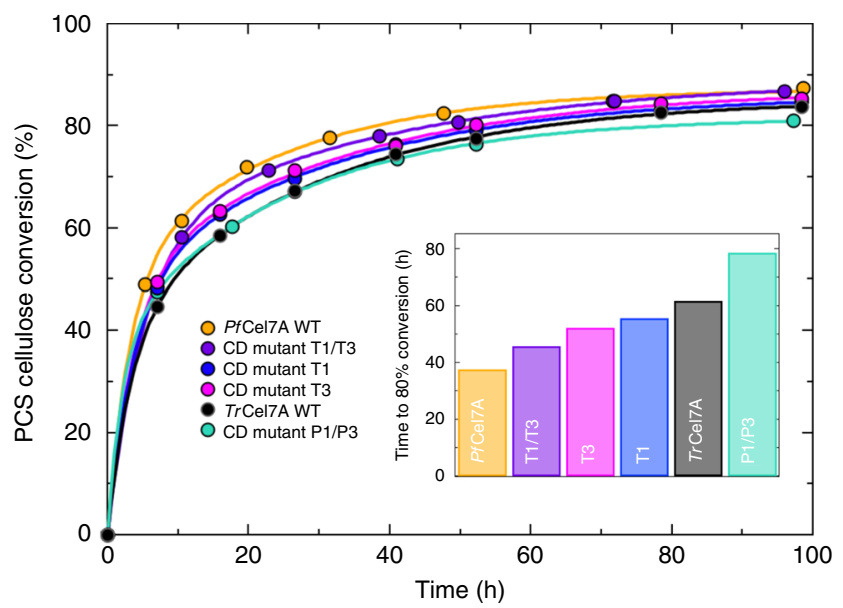

Fig. 4 Selected catalytic domain (CD) mutant activity data. T1 and T3 ( $T r C e l 7 A$ parent enzyme) show slight improvement in activity on pretreated corn stover (PCS) over WT TrCel7A, whereas combining these into the double mutant T1/T3 demonstrates activity comparable to WT PfCel7A. Experiments were performed in triplicate; error bars represent the SEM and are smaller than the data markers

The effect of the A1 loop shortening (deletion of Ala100, Gln101, Lys102) is seen in the surface simulations, where a "cascade effect", leads to large-scale rearrangements of loops A1, A2, and A3 (Fig. 5f), making other substrate-enclosing loops (e.g., B1, B2, A2, A4) significantly more flexible (Supplementary Fig. 10). The trigger for these widespread changes is likely the loss of the stabilizing salt bridge present in the WT between Lys102 (A1 loop) and Glu408 (A2 loop) (Fig. 5e), which leads to largescale movements of these loops to new equilibrium positions leading to the "opening" of the A3 loop as well (Fig. 5f). In addition to the lost salt bridge, both the solution and surface simulations reveal a stable hydrogen bond between the sidechain oxygen of Asn103 and the $\mathrm{O}_{2}$ hydroxyl group of the glucose in the -5 binding site in WT $\operatorname{TrCel7A}$ that is considerably more transient in the double mutant.

\section{Discussion}

GH7 CBHs are the cornerstone of modern industrial enzyme cocktails to deconstruct cellulose. Yet, despite a wealth of recent structural data, only a few self-consistent studies to date have directly related enzyme performance on relevant substrates at industrially relevant conversions to structural features. Recent years have seen many studies published on the details of the catalytic cycle of processive cellulases (often utilizing $\operatorname{TrCel7A}$ ), shedding light on the rate-limiting step (RLS) in deconstructing cellulose under various conditions $8,17,21,32,48,49,55,56$. Most cellulase engineering efforts to date have, however, not targeted a specific step of the processive cycle (namely, the RLS), but have instead tended to target more thermostable enzymes. Several such studies have addressed reducing end specific $\mathrm{CBHs}$ using an array of tools including biased DNA shuffling ${ }^{41}$, rational mutagenesis $^{18}$, consensus analysis of multiple sequence alignments ${ }^{57}$, SCHEMA $^{38,58}$, and directed evolution ${ }^{20,59}$; these often achieved higher activity due to higher operating temperature, and even enhanced synergism in an enzyme cocktail ${ }^{39}$.

In the current study, we employed a chimera library approach both at the domain (CBM, linker, CD) level and a more localized level, demonstrating that no single domain is fully responsible for the activity enhancement of WT PfCel7A over WT TrCel7A. This superiority was indicated previously, albeit at short incubation times and low conversions $(<25 \%)^{60}$, but is here demonstrated on real biomass to industrially relevant conversions in a synergistic enzyme cocktail. Elucidation of the crystal structure of the PfCel7A CD indicates local regions of structural variation from $\operatorname{TrCel7A}$, representing possible sources for the superior activity of the PfCel7A CD. By targeting these regions to produce a CD mutant library, it was found that two local structural changesremoval of a disulfide bond and shortening of a tunnel-enclosing loop, both near the tunnel entrance-impart a significant 


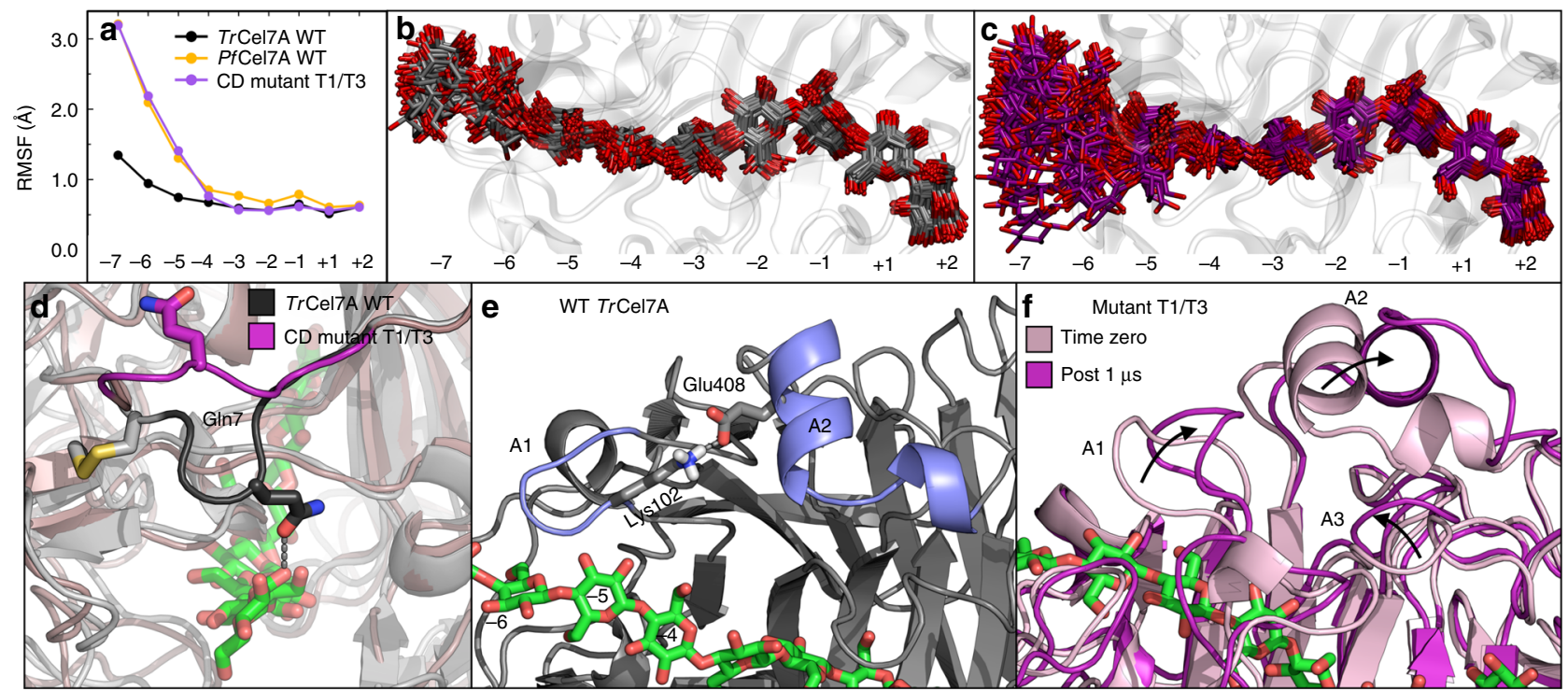

Fig. 5 Mechanistic insight from molecular simulations. a The RMSF profile for the glucosyl residue at each binding site in solution. This contrast in flexibility can be seen $\mathbf{b}$ in the WT TrCel7A, and $\mathbf{c}$ in the mutant enzyme, particularly at the $-5,-6$, and -7 subsites. The ligand is shown every $8 \mathrm{~ns}$ over $1 \mu$ s. $\mathbf{d}$ Whereas GIn7 in WT TrCel7A maintains a hydrogen bond with the glucosyl moiety in the -7 binding site, the mutant is more flexible, essentially abolishing this enzyme-substrate interaction at the tunnel entrance. e In the WT enzyme, a persistent salt bridge forms between Lys102 (A1 loop) and Glu408 (A2 loop). f The deletion of Lys102 results in the loss of this salt bridge in the mutant enzyme, resulting in significant rearrangements for loops A1, $\mathrm{A} 2$, and $\mathrm{A} 3$

improvement in performance on biomass when employed in an enzyme cocktail. MD simulations shed light on the structurefunction link by revealing increased ligand flexibility at the binding tunnel entrance as well as modulation of loop position and increased flexibility-characteristics likely to increase the ability to dissociate from a cellulose chain.

Kont et al. ${ }^{51}$ recently reported "inter-domain synergism" in $\operatorname{TrCel7A}$ wherein the effect of a W38A mutation at the CD tunnel entrance on the association constant $\left(k_{\text {on }}\right)$ was strongly dependent on whether the CBM-linker were attached, indicating some "compensation" between the variants in different domains. Our domain-swapping experiments indicate that chimeras with the PfCel7A CD tend to be the most active, but not uniformly so, demonstrating interrelatedness between domains, the source of which is not obvious. As such, the results presented in Fig. 2b suggest not only that significant performance improvements can be made to cellulases based on natural diversity screening and chimera library generation, but also motivate both further domain-swapping experiments in Family 7 (and other $\mathrm{GH}$ families) and further biophysical studies into the mechanism of multi-modular processive cellulases.

The rate-limiting step of cellulose deconstruction by processive GHs in the absence of synergistic polysaccharide-active enzymes such as non-reducing end specific CBHs, endoglucanases, and lytic polysaccharide monooxygenases (LPMO) is the dissociation rate $\left(k_{\text {off }}\right){ }^{48,61-64}$. Experimentally, we have mapped the superior activity of the PfCel7A CD (vs. TrCel7A) to two very localized regions of the structure and demonstrated via $\mathrm{MD}$ simulations enhanced flexibility of both substrate and enzyme in the CD mutant T1/T3, flexibility which could have a marked effect on $k_{\text {off }}$ Previous work has shown that rigidifying a substrateenclosing loop (B3 in this case) slightly decreases $\mathrm{CBH}$ processivity $^{52}$, suggesting a proportional increase in $k_{\text {off }}^{65}$, however, other modifications were also observed, including the loss of multiple hydrogen bonding interactions between the exo-loop and the substrate at the active site. We propose here that the most natural connection is that more flexible substrate-enclosing loops will likely, in general, result in a more efficient enzyme given its increased ability to dissociate when encountering an obstacle ${ }^{48,49}$. These connections are supported by recent mutagenesis experiments targeting loop regions in TeCel7A that showed enhanced cellulose hydrolysis when loop-loop and loop-substrate interactions were decreased ${ }^{66}$.

Connecting cellulase structural features with hydrolytic function is essential to the future success of engineering efforts, and ultimately to the development of industrial biochemical processes to produce fuels, chemicals, and materials from biomass. Going forward, more direct, self-consistent comparisons of the type presented here will be critical to successfully establishing this enhanced structure-function understanding. In addition, these comparisons must take place in a context that is as industrially applicable as possible, including relevant biomass types and loadings, in a synergistic cellulase cocktail, with assays conducted to high conversion extents. The current work has attempted to fulfill this, but even so, some aspects may warrant subsequent study such as whether a more complex cellulase background (e.g., in the presence of non-reducing end specific cellulases, additional endoglucanases, and LPMOs) could affect the results. Questions of this nature can only be resolved by further comparative structure-function studies at industrially relevant conditions.

\section{Methods}

Plasmids. All cellobiohydrolase $(\mathrm{CBH})$ enzymes were expressed using the pTrEno plasmid $^{45}$. The pTrEno vector is essentially an Enolase promoter driven expression integration vector selected for with hygromycin resistance. $\mathrm{CBH}$ genes were synthesized and cloned into the PacI and XbaI sites of pTrEno using either traditional ligation based cloning or using Gibson Assembly (New England Biolabs). To prep these plasmids for transformation the pTrEno-based plasmids containing the $\mathrm{CBH}$ gene were cut with $S b f I$ and $X h o I$ and integrated randomly into the genome.

Transformation of T. reesei. We used transformation by electroporation. Spores of AST1116 (QM6A CBH1 $\triangle:$ :AMDS) from a frozen glycerol stock were plated onto Potato Dextrose (PD) plates and allowed to grow for 3-5 days in a lighted incubator until the plates were green from abundant conidial spores. Spores were collected by spreading sterile deionized water $\left(\mathrm{diH}_{2} \mathrm{O}\right)$ onto the plates and recovering the spores in centrifuge tubes. Cells were adjusted to an $\mathrm{OD}_{600}$ of 0.03 in water and then $100 \mathrm{~mL}$ of cells were spread onto PD plates. These plates were grown in a lighted incubator at $30^{\circ} \mathrm{C}$ for two days. Spores were again harvested by 
spreading $5 \mathrm{~mL}$ of ice-cold sterile $\mathrm{diH}_{2} \mathrm{O}$ and using a sterile spreader to liberate the conidial spores from the mycelia. Spores were collected in $50 \mathrm{~mL}$ conical centrifuge tubes and were centrifuged for $5 \mathrm{~min}$ at $2000 \times \mathrm{g}$. Spores were washed twice with ice-cold sterile $\mathrm{diH}_{2} \mathrm{O}$ and twice with cold sterile $1 \mathrm{M}$ sorbitol repeating the above centrifuge conditions in between each wash. Spores were suspended in cold $1 \mathrm{M}$ sorbitol to a final $\mathrm{OD}_{600}$ of 2 . Spore aliquots were frozen on dry ice and stored indefinitely at $-80^{\circ} \mathrm{C}$.

Frozen spores aliquots were thawed on ice. To $75 \mu \mathrm{L}$ spore suspension we added $\sim 1 \mu \mathrm{g}$ of linearized DNA (see Plasmids section above) in a microcentrifuge tube. The DNA spore mixture was mixed and then transferred to a $0.1 \mathrm{~cm}$ gap electrocuvette (BioRad). These were then electroporated using the following settings on a BioRad Gene Pulser: $1.8 \mathrm{kV}, 800 \Omega, 25 \mu \mathrm{F}$. Immediately after delivering the pulse the cuvettes were placed back on ice for 5-10 min. Following this incubation, $1 \mathrm{~mL}$ of Complete Media with Lactose ["CML" per 1 liter: $5 \mathrm{~g}$ yeast extract, $5 \mathrm{~g}$ tryptone, $10 \mathrm{~g}$ lactose, autoclave, then cool, add $50 \mathrm{~mL}$ Clutterbucks Salts (per liter: $120.0 \mathrm{~g} \mathrm{NaNO}_{3}, 10.4 \mathrm{~g} \mathrm{KCl}, 10.4 \mathrm{~g} \mathrm{MgSO}_{4}, 30.4 \mathrm{~g} \mathrm{KH}_{2} \mathrm{PO}_{4}$ )] is added to the cuvette and then transferred to sterile tissue culture plates with either 6,12 , or 24 wells and allowed to recover overnight $(\sim 18 \mathrm{~h})$ at room temperature. Lactose is used for convenience because cells can recover overnight and the mycelial growth is minimal by the morning. In the morning, $200 \mu \mathrm{L}$ of cells are plated onto PDHX plates or PD plates supplemented with $100 \mu \mathrm{g} / \mathrm{mL}$ hygromycin and $0.1 \%$ v:v IGEPAL CA-630 (Similar to Triton X, Sigma-Aldrich). Plates were incubated at 30 ${ }^{\circ} \mathrm{C}$ for 2-3 days until colonies appeared.

Expression screening. Colonies were picked by coring out the agar using the wide end of a sterile $20-200 \mu \mathrm{L}$ pipette tip and inoculating $2-5 \mathrm{~mL}$ of a modified version of Mandels and Andreotti medium ${ }^{67}$ with glucose ("MAG", per liter $20 \mathrm{~mL}$ $50 \times$ Mandel's salts to $500 \mathrm{~mL}, 5 \mathrm{~g}$ tryptone, $\mathrm{H}_{2} \mathrm{O}$ to $720 \mathrm{~mL}$, pH to 5.5 with $\mathrm{KOH}$, autoclave, add $10 \mathrm{~mL}$ micronutrient solution, add $2.7 \mathrm{~mL} 1 \mathrm{M} \mathrm{CaCl}_{2}$, add $250 \mathrm{~mL}$ $20 \%$ glucose). 50× Mandel's salts per liter: $100 \mathrm{~g} \mathrm{KH}_{2} \mathrm{PO}, 70 \mathrm{~g}\left(\mathrm{NH}_{4}\right)_{2} \mathrm{SO}_{4}, 15 \mathrm{~g}$ urea, $15 \mathrm{~g} \mathrm{MgSO} .7 \mathrm{H}_{2} \mathrm{O}, \mathrm{pH}$ to 5.5 with $\mathrm{KOH}$. Micronutrient solution per liter: 500 $\mathrm{mg} \mathrm{FeSO}_{4} .7 \mathrm{H}_{2} \mathrm{O}, 160 \mathrm{mg}, \mathrm{MnSO}_{4} \cdot \mathrm{H}_{2} \mathrm{O}, 140 \mathrm{mg} \mathrm{ZnSO}{ }_{4}, 200 \mathrm{mg} \mathrm{CoCl}$. Picked colonies were incubated in sterile tissue culture plates statically at $30^{\circ} \mathrm{C}$ in a lighted incubator which allows for mycelial mats to form on the surface of the media; cellulases are secreted into the medium. After 2-3 days of growth, broth supernatants were screened by immunoblotting using an anti-P. funiculosum Cel7 antibody $(2.4 \mathrm{mg} / \mathrm{mL}$-custom made in rabbits by Robert Sargeant, 655 Ash Street, Ramona CA 92,065, and used at 1:2000 dilution), and an alkaline phosphatase conjugated goat anti-rabbit IgG antibody $(0.6 \mathrm{mg} / \mathrm{mL}$ - purchased at Thermo Scientific product \#31342 and used at 1:2000 dilution). For positive reacting clones, the mycelial mats were lifted from the suspension and placed onto PDH plates and allowed to sporulate for 2-3 days as described above. These spores were then restreaked onto PDHX plates for single colonies. Several single colonies were then grown up again in MAG and confirmed for expression.

Growth conditions for $\boldsymbol{T}$. reesei expression strains. Recombinant strains were streaked onto PD agar plates and allowed to grow 2-3 days until dense sporulation was achieved. A $\sim 0.5 \mathrm{~cm}$ plug was extracted from the plate and deposited into $1 \mathrm{~L}$ of liquid growth media in a $2.8 \mathrm{~L}$ shake flask. The growth media consisted of Mandel's growth media ${ }^{67}$ with $5 \%$ glucose as the carbon source, and $0.5 \%$ tryptone added. The culture was grown at $28^{\circ} \mathrm{C}$ with agitation for $24 \mathrm{~h}$, after which the entire $1 \mathrm{~L}$ was transferred to $7 \mathrm{~L}$ of the same media, in a bioreactor. The bioreactors are $15 \mathrm{~L}$ working volume vessels manufactured by New Brunswick and controlled via New Brunswick's BioFlo310 system. The total of $8 \mathrm{~L}$ was grown with mixing at $300 \mathrm{RPM}$ via dual down-flow marine style impellers, purged with $1.5 \mathrm{vvm}$ of filtered air, kept at a strict $28^{\circ} \mathrm{C}$, and $\mathrm{pH}$ controlled at 4.8 The acid and base used for $\mathrm{pH}$ control were $\mathrm{HCl}$ and $\mathrm{KOH}$, respectively. The cell culture was grown for 48 $\mathrm{h}$, after which the entire culture broth was drained, filtered through nylon to remove all cell mass, and concentrated via tangential flow filtration with a $10 \mathrm{kDa}$ MWCO (GE Health Sciences) concentrator. The concentrated broth was bufferexchanged into $20 \mathrm{mM}$ Bis-Tris buffer, $\mathrm{pH} 6.5$, and brought up to $\sim 200 \mathrm{~mL}$.

Purification of proteins. Culture supernatants were collected as follows. Mycelial mass was removed by gravity filtration using Miracloth (EMD Biosciences, Gibbstown, NJ). The supernatant obtained was passed under vacuum through a series of glass fiber filters with descending pore sizes ranging from 2.7 to $0.7 \mu \mathrm{m}$ (Millipore, Billerica, MA). This was followed by vacuum filtration through $0.45 \mu \mathrm{m}$ bottle-top filtration devices (Nalgene, Rochester, NY). After filtration, supernatants were concentrated to $\sim 2 \%$ of the original volume and exchanged into $20 \mathrm{mM}$ BisTris buffer, $\mathrm{pH} 6.5$ using a $10 \mathrm{kDa}$ MWCO hollow fiber tangential flow filtration system (GE Life Sciences QuixStand).

The concentrated supernatants were amended to $2 \mathrm{M}$ with solid $\left(\mathrm{NH}_{4}\right)_{2} \mathrm{SO}_{4}$ loaded onto a Tricorn 10/100 column (GE Healthcare, Piscataway, NJ) packed with Source 15Phe Hydrophobic Interaction Chromatography medium (GE Healthcare), and eluted using a 25 column volume linear gradient of $20 \mathrm{mM}$ Bis-Tris, $\mathrm{pH}$ 6.5, $1.8 \mathrm{M}\left(\mathrm{NH}_{4}\right)_{2} \mathrm{SO}_{4}$. Fractions were assayed for Cel7A activity by adding $25 \mu \mathrm{L}$ of each fraction to $100 \mu \mathrm{L}$ of $2.0 \mathrm{mM} p$-nitrophenol- $\beta$-lactopyranoside ( $p$ NPL; Sigma-Aldrich, St Louis, MO) in $50 \mathrm{mM}$ Sodium Acetate, pH 5.0 in a microtiter plate. Reactions were incubated for $30 \mathrm{~min}$ at $45^{\circ} \mathrm{C}$ and quenched by addition of $100 \mu \mathrm{L} 1.0 \mathrm{M}$ sodium carbonate. Absorbance was read at $405 \mathrm{~nm}$ and fractions with significant $p$ NPL activity were pooled and examined by SDS-PAGE and western blotting using polyclonal antibodies raised against the catalytic domain of T. reesei or P. funiculosum Cel7A, as required. Pooled peaks containing Cel7A were concentrated by centrifugal ultrafiltration using a $10 \mathrm{kDa}$ PES membrane (Viva Science) and desalted into $20 \mathrm{mM}$ Bis-Tris pH 6.5 using two Hi-Prep 26/10 desalting columns in series. The resultant protein solution was loaded onto a Tricorn 10/100 column packed with Source 15Q anion-exchange medium (GE Healthcare) and eluted with a 50 column volume linear gradient of $0-1.0 \mathrm{M} \mathrm{NaCl}$ in $20 \mathrm{mM}$ Bis-Tris pH 6.5. Fractions were assayed and visualized as above. Active fractions were pooled and amended to $2.0 \mathrm{M}\left(\mathrm{NH}_{4}\right)_{2} \mathrm{SO}_{4}$, and loaded onto a Tricorn 10/100 Source 15Iso hydrophobic interaction chromatography column, and eluted with a $1.8-0.0 \mathrm{M}\left(\mathrm{NH}_{4}\right)_{2} \mathrm{SO}_{4}$, gradient in $20 \mathrm{mM}$ Bis-Tris $\mathrm{pH}$ 6.5. Active fractions were pooled and concentrated to a volume $<13 \mathrm{~mL}$ in $10 \mathrm{kDa}$ MWCO Vivaspin-20 centrifugal concentration device and loaded onto a HiLoad Superdex 75 26/60 size exclusion column and eluted at $2.0 \mathrm{~mL} / \mathrm{min}$ in 20 $\mathrm{mM}$ Sodium Acetate, pH 5.0, $100 \mathrm{mM} \mathrm{NaCl}$. Fractions were assayed and visualized as above. Active fractions were pooled, concentrated as above, and protein concentration was determined as a function of absorbance at $280 \mathrm{~nm}$ using extinction coefficients specific to each protein sequence as calculated using Swiss-Prot.

Activity assays. CBH activity was measured as the saccharification of the cellulose fraction of a sample of a standard dilute-acid-pretreated corn stover by a given CBH species (loaded at $28 \mathrm{mg}$ CBH per $\mathrm{g}$ of biomass glucan) when used as part of a cocktail also containing two other glycolytic enzymes at standard loadings: (1) the endoglucanase Acidothermus cellulolyticus E1 (Cel5A, mutant Y245G, catalytic domain only ${ }^{68}$ at $1.894 \mathrm{mg} / \mathrm{g}$ of biomass cellulose to provide synergistic cellulolytic action with the $\mathrm{CBH}$ and (2) the chromatographically purified $\beta$-glucosidase from Aspergillus niger, loaded at $0.5 \mathrm{mg} / \mathrm{g}$ biomass cellulose to minimize product inhibition by cleaving product cellobiose to glucose.

The standard biomass substrate used in the activity assays was NREL diluteacid-pretreated corn stover ${ }^{69}$, ("pre-treated corn stover", PCS) P050921, produced in a vertical pulp digester supplied by Sunds Defibrator (now Metso Corporation, Helsinki) with a residence time of $\sim 1 \mathrm{~min}$ at $190^{\circ} \mathrm{C}$ with $0.45 \mathrm{~g} \mathrm{H}_{2} \mathrm{SO}_{4}$ per g dry biomass at $30 \%$ solids loading, to yield a material with $59.1 \%$ glucan, $5.1 \%$ xylan and $25.3 \%$ lignin. The PCS was washed first with water and then with $20 \mathrm{mM}$ acetic acid/sodium acetate buffer, $\mathrm{pH} 5.0$, until the $\mathrm{pH}$ of the (buffer) decantate was within 0.03 units of 5.00. From a slurry of this washed biomass material $(\sim 9 \mathrm{mg}$ biomass per $\mathrm{mL}$ of $\mathrm{pH} 5.0,20 \mathrm{mM}$ acetate buffer containing $0.02 \%$ sodium azide to retard microbial growth), a series of biomass substrate aliquots were prepared in $2.0 \mathrm{~mL}$ HPLC vials, in such a way that each vial contained $8.5 \mathrm{mg}$ biomass cellulose (which, given that the glucan content of this batch of PCS is $59.1 \%$, required 14.38 $\mathrm{mg}$ of biomass per digestion vial). Biomass dry weights for each batch of assay vials were verified by dry-weight determinations on a group of five samples co-pipetted into pre-tared vials. The acceptable relative standard deviation for a batch of biomass assay aliquots was $1 \%$ or less, with a preferred value of $0.8 \%$ or less. Adjustment of these biomass assay aliquots to a $1.7 \mathrm{~mL}$ final volume resulted in a cellulose concentration of $5 \mathrm{mg} / \mathrm{mL}$.

$\mathrm{CBH}$ assays were conducted in triplicate vials at $40^{\circ} \mathrm{C}$, pH 5.0 in $20 \mathrm{mM}$ azidecontaining acetate buffer, with continuous mixing by inversion at $10 \mathrm{RPM}$ while immersed in a water bath. At various times during the digestion, the digestion vials were removed from the rotator and representative $100 \mu \mathrm{L}$ samples containing both solids and liquid were removed from the well-stirred contents and diluted 18 -fold into glass HPLC vials. The primary digestion vials were immediately resealed and returned to the rotator in the assay $\left(40^{\circ} \mathrm{C}\right)$ water bath to allow the assay digestions to continue. The vials containing the withdrawn and diluted samples of digestion mixture were then crimp-sealed and immersed in a boiling-water bath for $10 \mathrm{~min}$ to denature the enzymes and terminate the reaction. The contents of the boiled time-sample vials were then syringe-filtered (0.2-micron Acrodisc) into a third set of vials for sugar analysis by HPLC on a BioRad HPX-87H column eluted at $55^{\circ} \mathrm{C}$ with $0.01 \mathrm{~N} \mathrm{H}_{2} \mathrm{SO}_{4}$ at $0.6 \mathrm{~mL} / \mathrm{min}$ with refractive-index detection. Values for individual sugar concentrations in the digestion vials were back-calculated from the values measured by HPLC, and then used to construct saccharification progresscurves in terms of percent of conversion of biomass cellulose.

PfCel7A and TrCel7A enzyme activity on pNPL. $V_{\max }$ and $K_{\mathrm{m}}$ were determined using $p$-nitrophenyl- $\beta$-D-lactopyranoside ( $p$ NPL, Sigma) as substrate. $0,0.13,0.26$, $0.66,1.3,2.6,5.3,6.6 \mathrm{mM} p \mathrm{NPL}(150 \mu \mathrm{L})$ was incubated with each $\mathrm{CBH}(25 \mu \mathrm{L})$ at $40^{\circ} \mathrm{C}$ in $20 \mathrm{mM}$ acetate buffer $\mathrm{pH} 5.0,100 \mathrm{mM} \mathrm{NaCl}$, in 96-well microtiter plates. Reactions were quenched by the addition of $25 \mu \mathrm{L}$ of $1.0 \mathrm{M}$ sodium carbonate after $30 \mathrm{~min}$. The absorbance values were converted to a molar concentration using pNPL standard curve (standards concentration range: $0-250 \mu \mathrm{M})$. Activity values were fit to the Michaelis-Menten expression using GraphPad Software (La Jolla, California USA). All reactions were carried out in triplicate.

PfCel7A and TrCel7A pH profile measurements. $\mathrm{pH}$ profiles were generated in duplicate by incubating $1.6 \mathrm{mM} p \mathrm{NPL}$ with $0.66 \mu \mathrm{M}$ indicated enzyme in $150 \mu \mathrm{L}$ of Macllvaine buffer (citrate-phosphate- $\mathrm{NaCl}$ ) with a constant conductivity between 19 and $21 \mathrm{mS} / \mathrm{cm}$. pH measurements were completed in a 96-well plate at $\mathrm{pH} 2.9$ 
$3.9,5.0,6.1,7.1$ and 8.3 at $40{ }^{\circ} \mathrm{C}$ for $0,1,5,10,20$, and $30 \mathrm{~min}$. The reaction was stopped by the addition of $25 \mu \mathrm{L}$ of $1.0 \mathrm{M}$ sodium carbonate and the $\mathrm{A}_{405}$ was determined by a colorimetric microtiter plate reader. The absorbance values were correlated to $p \mathrm{NPL}$ concentration via $p \mathrm{NP}$ standards and the $\mathrm{pH}$ profile graphs were generated by plotting the linear rate of $p \mathrm{NPL}$ turnover as a function of $\mathrm{pH}$.

PfCel7A and TrCel7A temperature profiles. Temperature profiles were generated in duplicate by incubating $1.6 \mathrm{mM} p \mathrm{NPL}$ with $0.66 \mu \mathrm{M}$ enzyme in $2.0 \mathrm{~mL}$ of $20 \mathrm{mM}$ acetate buffer $\mathrm{pH} 5$ or $\mathrm{pH} 4,100 \mathrm{mM} \mathrm{NaCl}$ and $0.02 \% \mathrm{NaN}_{3}$. Reactions were incubated at $30,35,40,45,50,55,60$, and $65^{\circ} \mathrm{C}$ in a water bath. At $0,1,5,10,20$, and $30 \mathrm{~min}, 150 \mu \mathrm{L}$ aliquots were removed from reaction vial to a 96 well plate containing $25 \mu \mathrm{L}$ of $1.0 \mathrm{M}$ sodium carbonate. Absorbance values were measured at $405 \mathrm{~nm}$ and temperature profile graphs were generated by plotting the linear rate of $p$ NPL turnover as a function of temperature.

Differential scanning calorimetry. Thermal stability was evaluated by differential scanning microcalorimetry (DSC) using a MicroCal model VP-DSC calorimeter (MicroCal, Inc., Northhampton, MA). Data were collected by Origin for DSC software (MicroCal). Samples contained $50 \mu \mathrm{g} / \mathrm{mL}$ protein at pH 5.0 in $20 \mathrm{mM}$ acetate, $100 \mathrm{mM} \mathrm{NaCl}$. Calorimeter scan rate was $60^{\circ} \mathrm{C} / \mathrm{h}$ with a range of $30-110^{\circ} \mathrm{C}$.

Deglycosylation. Before crystallization the purified PfCel7A was deglycosylated with jack bean alpha-mannosidase. For $1 \mathrm{mg}$ of PfCel7A 40 units of alphamannosidase (Sigma-Aldrich, St. Louis, MO, USA) were used in a buffer containing $100 \mathrm{mM}$ acetate $\mathrm{pH} 4.5,100 \mathrm{mM} \mathrm{NaCl}, 5 \%$ glycerol, and $1 \mathrm{mM}$ zinc acetate. The sample was then incubated at $37^{\circ} \mathrm{C}$ in a rotating incubator for $24 \mathrm{~h}$. After deglycosylation the alpha-mannosidase and partially deglycosylated PfCel7A were removed by repeating the anion exchange chromatography as described above and size exclusion chromatography using a 26/60 Superdex 75 column in $20 \mathrm{mM}$ acetate $\mathrm{pH}$ 5.0, $100 \mathrm{mM} \mathrm{NaCl}$, and $50 \mathrm{mM}$ cellobiose.

Crystallization. Crystals of the deglycosylated PfCel7A were initially detected with sitting-drop vapor diffusion crystallization using a 96-well plate, Grid Screen Salt HT from Hampton Research (Aliso Viejo, California, USA) and setup by a Phoenix crystallization robot (Art Robbins Instruments, Sunnyvale, California, USA). For the final data collection crystals were grown using a sitting drop setup with $50 \mu \mathrm{L}$ of well solution in the reservoirs and $0.5 \mu \mathrm{L}$ of well solution and $1.5 \mu \mathrm{L}$ of protein solution in the drop. The crystals grew at $20^{\circ} \mathrm{C}$ in $0.27 \mathrm{M}$ sodium phosphate monobasic monohydrate and $1.53 \mathrm{M}$ potassium phosphate dibasic $\mathrm{pH} 4.0$ as the well solution. The protein solution contained $15.5 \mathrm{mg} / \mathrm{mL}$ of protein in $20 \mathrm{mM}$ acetate $\mathrm{pH} 5.0,100 \mathrm{mM} \mathrm{NaCl}, 50 \mathrm{mM}$ cellobiose, and $5 \mathrm{mM}$ cellohexaose.

Data collection and processing. The PfCel7A crystal was flash frozen in a nitrogen gas stream at $100 \mathrm{~K}$ before data collection at $1.54178 \mathrm{~nm}$ wavelength using an in-house Bruker X8 MicroStar X-Ray generator with Helios mirrors and a Bruker Platinum 135 CCD detector. No cryoprotectants were used. Data were indexed and processed with the Bruker Suite of programs version v.2013.3 (Bruker AXS, Madison, WI)

Structure solution, refinement, and structure analysis. Intensities were converted into structure factors and 5\% of the reflections were flagged for $R_{\text {free }}$ calculations using programs F2MTZ, CTRUNCATE, CAD, and Unique from the CCP4 package of programs ${ }^{70}$. The program MOLREP ${ }^{71}$ version 11.2.05 was used for molecular replacement with Talaromyces emersonii Cel7A (PDB entry 3PL3) as the search model. Refinement and manual correction were performed using REFMAC5 $5^{72}$ version 5.8.0073 and Coot $^{73}$ version 0.7.1. MolProbity ${ }^{74}$ version 4.1 was used to analyze the Ramachandran plot and root mean square deviations (RMSD) of bond lengths and angles were calculated using ideal values of Engh and Huber stereochemical parameters ${ }^{75}$. According to Ramachandran plot statistics all residues were in the allowed regions, $98.1 \%$ were in the favored region and there were no outliers. Average B-factors, were calculated using program ICM version 3.8-0 (Molsoft LLC, La Jolla, CA). Programs Coot and PyMOL (http://www.pymol. org) were used for comparing and analyzing structures. The data collection and refinement statistics are shown in Table 1.

As discussed in the main text, the structure of the PfCel7A CD was solved to $1.70 \AA$ A resolution. As with essentially all GH7 family members with published crystal structures, the backbone of PfCel7A overlays that of $\operatorname{TrCel7A}$ quite closely. In the main text, we discussed various structural features wherein PfCel7A varies from $\operatorname{TrCel7A}$; we continue that discussion here. Another loop difference occurs on the "top" side of the enzyme (opposite the crystalline cellulose surface). This loop has three modes within GH7 crystal structures. $\operatorname{TrCel7A}$ possesses the shortest of these modes, whereas $P f C e l 7 \mathrm{~A}$ has the longest, a feature it shares with $P c \mathrm{Cel} 7 \mathrm{D}$ HirCel7A, ReCel7A, and TrCel7B.

At the binding tunnel entrance Tyr6 of PfCel7A sits above the decrystallized cellulose chain just beyond the -7 binding site (where Trp40 stacks on that glucosyl moiety). There is a high degree of variability at this residue in GH7 members with solved structures, and PfCel7A is the only of these to exhibit Tyr here. The space occupied by the side chain of PfCel7A Tyr6 is similar to that of PcCel7D Tyr47 and TrCel7B Tyr46.
The four tryptophan residues that line the binding tunnel in $\mathrm{GH} 7 \mathrm{CBH}$ are also found in PfCel7A (residues $40,38,371$, and 380 , which stack on the $-7,-4,-2$, and +1 glucosyl rings, respectively), and their positions overlay those of $\operatorname{TrCel7A}$ (as well as every other GH7 CBH) nearly perfectly. In addition, the catalytic residues (nucleophile Glu209, acid/base Glu214, and "helper" Asp211) overlay those of $\operatorname{TrCel7A}$ quite closely. At the product sites, PfCel7A shares a unique feature with $\mathrm{TrCel7A}$; whereas every other $\mathrm{GH} 7 \mathrm{CBH}$ has aspartate at residue 340 ( $T r C e l 7 A$ numbering), $T r C e l 7 A, P f C e l 7 A$, and ThCel7A have glycine. This acidic residue is within hydrogen bonding distance to the cellobiose product in the primed state close to the binding tunnel exit. Finally, the cellobiose captured in the product sites of the PfCel7A crystal structure is in "primed GEI" mode. In fact, the cellobiose product captured here is the closest to the tunnel exit that has been captured to date in a GH7 crystal structure.

Molecular simulations. Molecular dynamics (MD) simulations were performed both in solution and on the surface of a cellulose microfibril.

Solution simulations were performed with WT TrCel7A, WT PfCel7A, and CD mutant T1/T3. In each case, a cellononaose ligand was bound in the active site of the CD. Each enzyme was solvated in a box of explicit water molecules of approximate dimensions $80 \times 80 \times 80 \AA^{3}$. Sodium ions were added to neutralize the system. The total system size was $\sim 52,000$ atoms.

$\mathrm{MD}$ simulations on the surface a cellulose microfibril were performed for $\operatorname{TrCel7A}$ and CD mutant T1/T3. The construction of the surface simulations followed the protocol of Payne et al. ${ }^{33}$ The TrCel7A CD structure was taken from the Protein Data Bank 8CEL with a cellononaose ligand in the tunnel to form the catalytically active complex ${ }^{12}$. The cellulose microfibril is 28 units long with four layers of cellulose chains. The top layer comprises three chains. $\operatorname{TrCel7A}$ is complexed with an edge chain of the top layer on the hydrophobic face of cellulose. Each system contained $\sim 116,000$ atoms with dimensions of $\sim 160 \times 80 \times 80 \AA^{3}$.

The initial simulation of WT $\operatorname{TrCel7A}$ (fully glycosylated) began with the linker unbound and $\sim 12$ glucose residues of the complexed chain displaced from their crystal structure positions within the microfibril surface. The CD mutant T1/T3 was built from this system after 200 ns of unrestrained molecular dynamics. In this time period, several residues of the cellulose chain anneal back into the surface, leaving only nine glucose residues outside of the microfibril. The linker domain also binds to the cellulose surface within $200 \mathrm{~ns}$. Thus, the mutant simulation begins with the linker bound and the complexed cellulose chain in a relaxed configuration. From this point, both systems were simulated for an additional $1 \mu \mathrm{s}$.

Additional details on the molecular simulations can be found in the Supplementary Methods.

Data availability. PfCel7A crystal structure is available in the Protein Data Bank (PDB) under accession number 4XEB. The data that support the findings of this study are available from the corresponding author on reasonable request.

Received: 8 August 2017 Accepted: 16 February 2018

Published online: 22 March 2018

\section{References}

1. Cosgrove, D. J. Growth of the plant cell wall. Nat. Rev. Mol. Cell. Biol. 6, 850-861 (2005)

2. Somerville, C. et al. Toward a systems approach to understanding plant cell walls. Science 306, 2206-2211 (2004).

3. Atsumi, S., Hanai, T. \& Liao, J. C. Non-fermentative pathways for synthesis of branched-chain higher alcohols as biofuels. Nature 451, 86-89 (2008).

4. Peralta-Yahya, P. P., Zhang, F., del Cardayre, S. B. \& Keasling, J. D. Microbial engineering for the production of advanced biofuels. Nature 488, 320-328 (2012).

5. Roman-Leshkov, Y., Barrett, C. J., Liu, Z. Y. \& Dumesic, J. A. Production of dimethylfuran for liquid fuels from biomass-derived carbohydrates. Nature 447, 982-985 (2007).

6. Himmel, M. E. et al. Biomass recalcitrance: engineering plants and enzymes for biofuels production. Science 315, 804-807 (2007).

7. Humbird, D. et al. Process design and economics for biochemical conversion of lignocellulosic biomass to ethanol: dilute-acid pretreatment and enzymatic hydrolysis of corn stover. Report No. NREL/TP-5100-47764 (National Renewable Energy Laboratory, Golden, 2011).

8. Payne, C. M. et al. Fungal cellulases. Chem. Rev. 115, 1308-1448 (2015)

9. Lynd, L. R., Weimer, P. J., Van Zyl, W. H. \& Pretorius, I. S. Microbial cellulose utilization: fundamentals and biotechnology. Microbiol. Mol. Biol. Rev. 66, 506-577 (2002)

10. Cragg, S. M. et al. Lignocellulose degradation mechanisms across the tree of life. Curr. Opin. Chem. Biol. 29, 108-119 (2015).

11. Divne, C. et al. The three-dimensional crystal structure of the catalytic core of cellobiohydrolase I from Trichoderma reesei. Science 265, 524-528 (1994). 
12. Divne, C., Ståhlberg, J., Teeri, T. T. \& Jones, T. A. High-resolution crystal structures reveal how a cellulose chain is bound in the $50 \AA$ long tunnel of cellobiohydrolase I from Trichoderma reesei. J. Mol. Biol. 275, 309-325 (1998).

13. Grassick, A. et al. Three-dimensional structure of a thermostable native cellobiohydrolase, $\mathrm{CBH}$ IB, and molecular characterization of the cel7 gene from the filamentous fungus. Talaromyces Emersonii. Eur. J. Biochem. 271, 4495-4506 (2004).

14. Kern, M. et al. Structural characterization of a unique marine animal Family 7 cellobiohydrolase suggests a mechanism of cellulase salt tolerance. Proc. Natl Acad. Sci. USA 110, 10189-10194 (2013).

15. Muñoz, I. G. et al. Family 7 cellobiohydrolases from Phanerochaete chrysosporium: crystal structure of the catalytic module of Cel7D (CBH58) at $1.32 \AA$ resolution and homology models of the isozymes. J. Mol. Biol. 314, 1097-1111 (2001).

16. Parkkinen, T., Koivula, A., Vehmaanpera, J. \& Rouvinen, J. Crystal structures of Melanocarpus albomyces cellobiohydrolase Cel7B in complex with cellooligomers show high flexibility in the substrate binding. Protein Sci. 17, 1383-1394 (2008).

17. Knott, B. C. et al. The mechanism of cellulose hydrolysis by a two-step, retaining cellobiohydrolase elucidated by structural and transition path sampling studies. J. Am. Chem. Soc. 136, 321-329 (2014).

18. Voutilainen, S. P., Murray, P. G., Tuohy, M. G. \& Koivula, A. Expression of Talaromyces emersonii cellobiohydrolase Cel7A in Saccharomyces cerevisiae and rational mutagenesis to improve its thermostability and activity. Protein Eng. Des. Sel. 23, 69-79 (2010).

19. Voutilainen, S. P. et al. Cloning, expression, and characterization of novel thermostable family 7 cellobiohydrolases. Biotechnol. Bioeng. 101, 515-528 (2008).

20. Wu, I. \& Arnold, F. H. Engineered thermostable fungal Cel6A and Cel7A cellobiohydrolases hydrolyze cellulose efficiently at elevated temperatures. Biotechnol. Bioeng. 110, 1874-1883 (2013).

21. Knott, B. C., Crowley, M. F., Himmel, M. E., Ståhlberg, J. \& Beckham, G. T. Carbohydrate-protein interactions that drive processive polysaccharide translocation in enzymes revealed from a computational study of cellobiohydrolase processivity. J. Am. Chem. Soc. 136, 8810-8819 (2014).

22. Textor, L. C. et al. Joint X-ray crystallographic and molecular dynamics study of cellobiohydrolase I from Trichoderma harzianum: deciphering the structural features of cellobiohydrolase catalytic activity. FEBS J. 280, 56-69 (2013).

23. Beckham, G. T. et al. The O-glycosylated linker from the Trichoderma reesei Family 7 cellulase is a flexible, disordered protein. Biophys. J. 99, 3773-3781 (2010).

24. Kraulis, J. et al. Determination of the three-dimensional solution structure of the C-terminal domain of cellobiohydrolase I from Trichoderma reesei. A study using nuclear magnetic resonance and hybrid distance geometrydynamical simulated annealing. Biochemistry 28, 7241-7257 (1989).

25. Abuja, P. M. et al. Structural and functional domains of cellobiohydrolase I from Trichoderma reesei. Eur. Biophys. J. 15, 339-342 (1988).

26. Linder, M., Lindeberg, G., Reinikainen, T., Teeri, T. T. \& Pettersson, G. The difference in affinity between 2 fungal cellulose-binding domains is dominated by a single amino-acid substitution. FEBS Lett. 372, 96-98 (1995).

27. Linder, M. et al. Identification of functionally important amino-acids in the cellulose-binding domain of Trichoderma reesei cellobiohydrolase I. Protein Sci. 4, 1056-1064 (1995).

28. Linder, M. \& Teeri, T. T. The cellulose-binding domain of the major cellobiohydrolase of Trichoderma reesei exhibits true reversibility and a high exchange rate on crystalline cellulose. Proc. Natl Acad. Sci. USA 93, 12251-12255 (1996)

29. Taylor, C. B. et al. Computational investigation of glycosylation effects on a Family 1 carbohydrate-binding module. J. Biol. Chem. 287, 3147-3155 (2012).

30. Chen, L. et al. Specificity of $O$-glycosylation in enhancing the stability and cellulose binding affinity of Family 1 carbohydrate-binding modules. Proc. Natl Acad. Sci. USA 111, 7612-7617 (2014).

31. Guan, X. et al. Molecular-scale features that govern the effects of $O$-glycosylation on a carbohydrate-binding module. Chem. Sci. 6, 7185-7189 (2015).

32. Igarashi, K. et al. High speed atomic force microscopy visualizes processive movement of Trichoderma reesei cellobiohydrolase I on crystalline cellulose. J. Biol. Chem. 284, 36186-36190 (2009).

33. Payne, C. M. et al. Glycosylated linkers in multi-modular lignocellulose degrading enzymes dynamically bind to cellulose. Proc. Natl Acad. Sci. USA 110, 14646-14651 (2013).

34. Jalak, J. \& Valjamae, P. Mechanism of initial rapid rate retardation in cellobiohydrolase catalyzed cellulose hydrolysis. Biotechnol. Bioeng. 106 871-883 (2010).

35. Beckham, G. T. et al. Towards a molecular-level theory of carbohydrate processivity in glycoside hydrolases. Curr. Opin. Biotechnol. 27, 96-106 (2014).

36. Beckham, G. T. et al. Harnessing glycosylation to improve cellulase activity. Curr. Opin. Biotechnol. 23, 338-345 (2012).
37. Jeoh, T., Michener, W., Himmel, M. E., Decker, S. R. \& Adney, W. S. Implications of cellobiohydrolase glycosylation for use in biomass conversion. Biotechnol. Biofuels 1, 10 (2008)

38. Smith, M. A., Bedbrook, C. N., Wu, T. \& Arnold, F. H. Hypocrea jecorina cellobiohydrolase I stabilizing mutations identified using noncontiguous recombination. ACS Synth. Biol. 2, 690-696 (2013).

39. Trudeau, D. L., Lee, T. M. \& Arnold, F. H. Engineered thermostable fungal cellulases exhibit efficient synergistic cellulose hydrolysis at elevated temperatures. Biotechnol. Bioeng. 111, 2390-2397 (2014).

40. Moraïs, S. et al. Enhancement of cellulosome-mediated deconstruction of cellulose by improving enzyme thermostability. Biotechnol. Biofuels. 9, 164 (2016).

41. Dana, C. M. et al. Biased clique shuffling reveals stabilizing mutations in cellulase Cel7A. Biotechnol. Bioeng. 109, 2710-2719 (2012).

42. Heinzelman, P. et al. A family of thermostable fungal cellulases created by structure-guided recombination. Proc. Natl Acad. Sci. USA 106, 5610-5615 (2009).

43. Lantz, S. E. et al. Hypocrea jecorina Cel6A protein engineering. Biotechnol. Biofuels 3, 20 (2010).

44. Ogunmolu, F. E. et al. Proteomics insights into the biomass hydrolysis potentials of a hypercellulolytic fungus Penicillium funiculosum. J. Proteome Res. 14, 4342-4358 (2015).

45. Linger, J. G. et al. A constitutive expression system for glycosyl hydrolase family 7 cellobiohydrolases in Hypocrea jecorina. Biotechnol. Biofuels 8, 45 (2015).

46. Kádár, Z., Szengyel, Z. \& Réczey, K. Simultaneous saccharification and fermentation (SSF) of industrial wastes for the production of ethanol. Ind. Crops Prod. 20, 103-110 (2004).

47. Sakon, J., Adney, W. S., Himmel, M. E., Thomas, S. R. \& Karplus, P. A. Crystal structure of thermostable Family 5 endocellulase E1 from Acidothermus cellulolyticus in complex with cellotetraose. Biochemistry 35, 10648-10660 (1996).

48. Kurasin, M. \& Valjamae, P. Processivity of cellobiohydrolases is limited by the substrate. J. Biol. Chem. 286, 169-177 (2011).

49. Jalak, J., Kurasin, M., Teugjas, H. \& Valjamae, P. Endo-exo synergism in cellulose hydrolysis revisited. J. Biol. Chem. 287, 28802-28815 (2012).

50. Aden, A. et al. Lignocellulosic biomass to ethanol process design and economics utilizing co-current dilute acid prehydrolysis and enzymatic hydrolysis for corn stover. Report No. NREL/TP-510-32438 (National Renewable Energy Laboratory, Golden, 2002).

51. Kont, R., Kari, J., Borch, K., Westh, P. \& Valjamae, P. Inter-domain synergism is required for efficient feeding of cellulose chain into active site of cellobiohydrolase Cel7A. J. Biol. Chem. 291, 26013-26023 (2016).

52. von Ossowski, I. et al. Engineering the exo-loop of Trichoderma reese cellobiohydrolase, Cel7A. A comparison with Phanerochaete chrysosporium Cel7D. J. Mol. Biol. 333, 817-829 (2003).

53. Momeni, M. H. et al. Structural, biochemical, and computational characterization of the glycoside hydrolase Family 7 cellobiohydrolase of the tree-killing fungus Heterobasidion irregulare. J. Biol. Chem. 288, 5861-5872 (2013).

54. Momeni, M. H. et al. Expression, crystal structure and cellulase activity of the thermostable cellobiohydrolase Cel7A from the fungus Humicola grisea var. thermoidea. Acta Crystallogr. Sect. D Biol. Crystallogr. 70, 2356-2366 (2014).

55. Igarashi, K. et al. Traffic jams reduce hydrolytic efficiency of cellulase on cellulose surface. Science 333, 1279-1282 (2011).

56. Sorensen, T. H., Cruys-Bagger, N., Borch, K. \& Westh, P. Free energy diagram for the heterogeneous enzymatic hydrolysis of glycosidic bonds in cellulose. J. Biol. Chem. 290, 22203-22211 (2015).

57. Komor, R. S., Romero, P. A., Xie, C. B. \& Arnold, F. H. Highly thermostable fungal cellobiohydrolase I (Cel7A) engineered using predictive methods. Protein Eng. Des. Sel. 25, 827-833 (2012)

58. Heinzelman, P. et al. Efficient screening of fungal cellobiohydrolase class I enzymes for thermostabilizing sequence blocks by SCHEMA structure-guided recombination. Protein Eng. Des. Sel. 23, 871-880 (2010).

59. Voutilainen, S. P. et al. Heterologous expression of Melanocarpus albomyces cellobiohydrolase Cel7B, and random mutagenesis to improve its thermostability. Enzym. Microb. Technol. 41, 234-243 (2007).

60. Ogunmolu, F. E. et al. Comparative insights into the saccharification potentials of a relatively unexplored but robust Penicillium funiculosum glycoside hydrolase 7 cellobiohydrolase. Biotechnol. Biofuels. 10, 71 (2017)

61. Cruys-Bagger, N. et al. Pre-steady-state kinetics for hydrolysis of insoluble cellulose by cellobiohydrolase Cel7A. J. Biol. Chem. 287, 18451-18458 (2012).

62. Cruys-Bagger, N., Tatsumi, H., Ren, G. R., Borch, K. \& Westh, P. Transient kinetics and rate-limiting steps for the processive cellobiohydrolase Cel7A: effects of substrate structure and carbohydrate binding domain. Biochemistry 52, 8938-8948 (2013)

63. Kari, J. et al. Kinetics of cellobiohydrolase (Cel7A) variants with lowered substrate affinity. J. Biol. Chem. 289, 32459-32468 (2014).

64. Cruys-Bagger, N. et al. Rate of threading a cellulose chain into the binding tunnel of a cellulase. J. Phys. Chem. B 120, 5591-5600 (2016). 
65. Horn, S. J., Sorlie, M., Varum, K. M., Valjamae, P. \& Eijsink, V. G. Measuring processivity. Methods Enzymol. 510, 69-95 (2012).

66. Sorensen, T. H. et al. Loop variants of the thermophile Rasamsonia emersonii Cel7A with improved activity against cellulose. Biotechnol. Bioeng. 114, 53-62 (2016).

67. Mandels, M. \& Andreotti, R. E. Problems and challenges in the cellulose to cellulase fermentation. Process Biochem. 13, 6-13 (1978).

68. Baker, J. O. et al. Catalytically enhanced endocellulase Cel5A from Acidothermus cellulolyticus. Appl. Biochem. Biotechnol. 121-124, 129-148 (2005).

69. Schell, D. J., Farmer, J., Newman, M. \& McMillan, J. D. Dilute-sulfuric acid pretreatment of corn stover in pilot-scale reactor: investigation of yields, kinetics, and enzymatic digestibilities of solids. Appl. Biochem. Biotechnol. 105, 69-85 (2003).

70. Winn, M. D. et al. Overview of the CCP4 suite and current developments. Acta Crystallogr. Sect. D. Biol. Crystallogr. 67, 235-242 (2011).

71. Vagin, A. \& Teplyakov, A. Molecular replacement with MOLREP. Acta Crystallogr. Sect. D. Biol. Crystallogr. 66, 22-25 (2010).

72. Murshudov, G. N. et al. REFMAC5 for the refinement of macromolecular crystal structures. Acta Crystallogr. Sect. D. Biol. Crystallogr. 67, 355-367 (2011).

73. Emsley, P., Lohkamp, B., Scott, W. G. \& Cowtan, K. Features and development of Coot. Acta Crystallogr. Sect. D. Biol. Crystallogr. 66, 486-501 (2010).

74. Chen, V. B. et al. MolProbity: all-atom structure validation for macromolecular crystallography. Acta Crystallogr. Sect. D Biol. Crystallogr. 66, 12-21 (2010).

75. Engh, R. A. \& Huber, R. Accurate bond and angle parameters for X-ray protein structure refinement. Acta Crystallogr. A 47, 392-400 (1991).

76. Zhong, L. et al. Computational simulations of the Trichoderma reese cellobiohydrolase I acting on microcrystalline cellulose $\mathrm{I} \beta$ : the enzymesubstrate complex. Carbohydr. Res. 344, 1984-1992 (2009).

\section{Acknowledgements}

We thank the US Department of Energy, Energy Efficiency and Renewable Energy Bioenergy Technologies Office for funding under Contract DE-

AC36-08GO28308 with the National Renewable Energy Laboratory. Computer time was provided by Extreme Science and Engineering Discovery

Environment (XSEDE) allocation MCB-090159 at the Texas Advanced Computing

Center and by the National Renewable Energy Laboratory Computational Sciences Center supported by the DOE Office of EERE under contract number DE-

AC36-08GO28308. YBC was supported by Indo-US Science \& Technology ForumBioenergy-Awards for Cutting Edge Research (B-ACER) grant, Govt. of India. The U.S. Government retains and the publisher, by accepting the article for publication, acknowledges that the U.S. Government retains a nonexclusive, paid up, irrevocable, worldwide license to publish or reproduce the published form of this work, or allow others to do so, for U.S. Government purposes.

\section{Author contributions}

L.E.T., W.S.A., M.E.H., S.R.D., and G.T.B. designed the study, L.E.T., B.C.K., J.O.B., P.M A., S.E.H., J.G.L., V.V.L., A.A., V.S., K.P., Q.X., T.A.V., L.A.S., Y.B.C., and S.R.D. conducted the experiments, L.E.T., B.C.K., J.O.B., P.M.A., M.F.C., S.R.D., and G.T.B. analyzed the data, B.C.K., and G.T.B. wrote the first draft of the manuscript, which was edited and approved by all authors.

\section{Additional information}

Supplementary Information accompanies this paper at https://doi.org/10.1038/s41467018-03501-8.

Competing interests: W.S.A., J.O.B., S.R.D., M.E.H., G.T.B., L.E.T., J.G.L., K.P., and Q.X. hold a patent related to PfCel7A and chimeric enzymes. The remaining authors declare no competing interests.

Reprints and permission information is available online at http://npg.nature.com/ reprintsandpermissions/

Publisher's note: Springer Nature remains neutral with regard to jurisdictional claims in published maps and institutional affiliations.

(c) (i) Open Access This article is licensed under a Creative Commons Attribution 4.0 International License, which permits use, sharing, adaptation, distribution and reproduction in any medium or format, as long as you give appropriate credit to the original author(s) and the source, provide a link to the Creative Commons license, and indicate if changes were made. The images or other third party material in this article are included in the article's Creative Commons license, unless indicated otherwise in a credit line to the material. If material is not included in the article's Creative Commons license and your intended use is not permitted by statutory regulation or exceeds the permitted use, you will need to obtain permission directly from the copyright holder. To view a copy of this license, visit http://creativecommons.org/ licenses/by/4.0/.

(c) The Author(s) 2018 